\title{
CRITERIA FOR SELECTING DESIGN PROCESS MODELLING APPROACHES
}

\author{
Trauer, Jakob (1); \\ Wöhr, Ferdinand $(1,2)$; \\ Eckert, Claudia (3); \\ Kannengiesser, Udo (4); \\ Knippenberg, Sjoerd (5); \\ Sankowski, Olga (6); \\ Zimmermann, Markus (1) \\ 1: Technical University of Munich; \\ 2: BMW Group; \\ 3: The Open University; \\ 4: Johannes Kepler University; \\ 5: Eindhoven University of Technology; \\ 6: Hamburg University of Technology
}

\begin{abstract}
Process models are among the principal artefacts used for managing design projects. However, the selection of effective modelling approaches can be difficult for design project managers, given that a plethora of tools exists for various modelling purposes. In addition to date no systematic approach for the assessment and selection of process modelling approaches is available to practitioners. This paper presents the development of criteria for benchmarking and selecting different process modelling tools. The results are based on three elements. (1) In a four-hour workshop undertaken by the Design Process SIG of the Design Society, bringing together around 20 international researchers and practitioners in design process modelling, an initial set of 58 criteria were brainstormed and consolidated during the workshop and in follow-up meetings. (2) The consolidated criteria were then compared with literature. The finalised criteria list was then validated by external experts in industry (3). The resulting list of 12 criteria provides a sound basis for practitioners to support a systematic selection of process modelling approaches. Further, it lays the foundation of a benchmarking tool, which is subject to future work.
\end{abstract}

Keywords: Criteria, Design process, Process modelling, Decision making, Benchmarking

Contact:

Trauer, Jakob

Technical University of Munich

Laboratory for Product Development and Lightweight Structures

Germany

jakob.trauer@tum.de

Cite this article: Trauer, J., Wöhr, F., Eckert, C., Kannengiesser, U., Knippenberg, S., Sankowski, O., Zimmermann, M. (2021) 'Criteria for Selecting Design Process Modelling Approaches', in Proceedings of the International Conference on Engineering Design (ICED21), Gothenburg, Sweden, 16-20 August 2021. DOI:10.1017/pds.2021.79 


\section{INTRODUCTION}

Complex products are designed by dozens and sometimes hundred and thousands of people over long periods of time. These processes need to be planned, coordinated, and monitored throughout the product development process. Individuals need to understand how their activities fit into the activities that others carry out. Browning and Ramasesh (2007) point out that "Product development (PD) comprises the myriad of multifunctional activities carried out by a firm from the beginning when 'defining a technological or market opportunity' to 'starting production'. However, the product development process is curious elusive, as different people experience and describe it different ways (Checkland 1999). The only way to interact with a process is through models of the process. Engineers in industry use a variety of different information artefacts as ways means of planning and structuring their own activities and those of their area of responsibility whereby expert use a variety of different representations and trade them of against each other (Eckert and Clarkson 2010). Engineers interpret process models as being binding to varying degree, depending on whether they can actively influence the process (Stacey et al. 2020). To gain a shared understanding and interact with processes in a more effective way, companies increasingly aim to model their processes in a standardised tool, which is used across the organisation. Different software vendors offer process modelling environments, which are built on a variety of different underlying modelling approaches. What modelling approach is suitable depends on the purpose of the model, the understanding of the process and the ability, time and effort the modellers are willing to invest (Gericke et al. 2016a). This makes the selection of a suitable modelling environment a challenging task, especially if multiple aspects need be considered. A wrong choice due to time pressure or lack of awareness can have significant effects on the outcome. Besides being inefficient because the selected approach does not, or only in parts, fulfil the intended purpose, inadequate process modelling environments can also lead to a general rejection of process modelling practices since the users do not recognize their actual benefit. The selection of a suitable modelling approach can have a significant impact on the effectiveness and efficiency of product development. This paper addresses the specific what criteria are suitable to select process modelling approach and offers a list of potential selection criteria.

Once a process modelling approach has been selected, a company can then proceed to selecting a specific modelling tool from a particular vendor. In practise the modelling approach and the modelling tools are often seen as a unit. However, as the selection of a software tool is tight up with multiple usability issues, this paper focusses on the modelling approach, i.e., the entities that are modelled, the relations that can exist and the analyses that can be carried out.

This paper has arisen from a workshop run by the design process special interest group (formally known as Modelling and Managing Engineering Processes - MMEP) of the Design Society in February 2019 at the University of Rostock. The workshop brought around 20 researchers and practitioners from Germany, the United Kingdom, the Netherlands, and Sweden together to address the question of "Benchmarking process modelling and management tools". The participants all have a background in engineering design. In general terms two forms of benchmarking can be distinguished (see Stapenhurst 2009): producer driven benchmarking looks at comparing the producer's product against competing products and user benchmarking, where a user compares a set of similar products. In both cases one of the key questions is: by which criteria are the products compared? In product driven benchmarking this is carried out by product experts, who know which criteria matter to them. The users in user driven benchmarking do not necessarily have a complete enough picture or the time to select a suitable range of criteria.

The paper presents a compiled list of criteria resulting from a brainstorming workshop, subsequent literature review, follow-up discussions amongst the authors, and interviews with industry experts. This paper is a companion paper to a paper, which has arisen from the same workshop, on process modelling scenarios, which identifies use cases and personas in different process modelling situations (see Helten et al. under review). Together the two papers enable decision makers in organisation to make more informed choices about the selection of suitable process modelling tools.

\section{METHODOLOGY}

The workshop identified selection criteria as an important issue in benchmarking process modelling approaches. The participating practitioners pointed out that even when no systematic benchmarking takes place, selection and evaluation criteria are still important. In practice, a preselection of a 
modelling tool might already have taken place, but practitioners might need criteria to assess a potential tool and voice their concerns before a company commits significant funding.

The authors of this paper formed a breakout group to address the issue of selection criteria and conducted a four-hour working session. The session started with a brainstorming exercise, where everybody noted down all the criteria they could think of. This yielded in 58 post-it notes created. The criteria were afterwards clustered by group and names, resulting in 11 consolidated criteria. These toplevel cluster criteria were discussed to establish a shared understanding of the criteria definition.

Subsequently the first and second author conducted a literature review of selection criteria for models. For this literature review the databases "Scopus" and "Web of Science" were used. The research revealed that the workshop had yielded most of the different criteria but clarified the vocabulary. The criteria where than discussed again among the group of authors.

For final validation two interviews were conducted with industry experts to understand the criteria they would usually use and gain their feedback on the list presented in this paper. The first interviewee is responsible for development processes as part of the project management office of a medium sized German company producing construction machines. Not only from his work experience in general, but also from his academic background, he has extensive knowledge and experience in process modelling and the respective approaches. The second industry expert works at a German company producing home appliances. As well as the first interviewee, he is responsible for the administration, management, and modelling of development processes. Thus, he also provides extensive knowledge and working experiences with respect to process modelling approaches. Both one-hour interviews were conducted by the first two authors of the present paper as well as the first author of the paper of Helten et al. (2021).

\section{DIVERSITY OF PROCESS MODELLING APPROACHES}

Wynn and Clarkson (2018) divide process models into procedural models that express best practice, abstract models that provide a conceptualisation of design processes largely for research and teaching, mathematical management science or operation research models for computational analysis, and analysis models, which provide situation-specific insights, improvements, and support for particular processes. The processes can describe a generic macro level, a very detailed micro level or a meso level which include a high degree of abstraction, which reflect a specific process or company. Industry is largely concerned with analytical meso level models, which involve considerable skills and judgement to model. Analytical process models, which are the focus here, are defined as models used to represent the details and elements of a particular development and design process and are suitable for analysing and improving design processes (Wynn and Clarkson 2018). Applying process modelling approaches provides insights for product or process design and helps with improving operations as well as financial and feasibility assessments (Cameron and Ingram 2008). There are plenty of different approaches and even more techniques and computer systems to achieve this goal. According to Wynn and Clarkson (2018), there are 23 different modelling approaches for meso-level analytical models, which they further divided into five subcategories: task precedence models, task dependency models or domain-integrating task network models, rule-based models, and agent-based task network models.

Well-known examples for task precedence models are e.g., control-flow oriented business process models (BPM), or Gantt-charts. Detailed overviews of these traditional BPM approaches can be found in e.g., Aguilar-Savén (2004) or Giaglis (2001). A more recent BPM approach (Fleischmann et al. 2012), which is increasingly used for engineering and production management, conceptualises a process as a set of modular behaviour specifications interlinked by messages. Gantt-charts also provide an effective way to model and visualise project plans. In this case tasks and their durations are displayed as horizontal bars and connected by a Start-to-Start, Finish-to-Start or Finish-to-Finish relationship. They are often used in industry because of their simplicity and ease of use. The task design structure matrix (DSM) is an example for a task dependency model, showing the tasks necessary to achieve the goal and their information dependencies. Applying the task DSM helps to decide, whether tasks can be executed sequentially or in parallel. A purpose-oriented categorisation of domain-integrating task network models was presented by Eckert et al. (2017). These kinds of models combine process and product information and are useful to analyse interrelations and guide trade-offs between those processes. Examples are the multi-domain matrix (MDM) (see Eppinger and Browning 
2019) or the DEPNET approach (see Ouertani et al. 2007). Finally, Signposting, a rule-based model, discussed by Wynn et al. (2006), is another modelling technique, which can be used in order to analyse and optimize design processes.

However, it is not clear how exactly practitioners choose from this variety of process modelling approaches and techniques. It is well known that companies often prescribe tools and approaches (Wynn and Clarkson 2018). Yet, these tools might not cover all purposes. Consequently, there is not one model or approach used exclusively in a company, but a partial use of different models (Eckert et al. 2017). Once adopted they are used for a long time, even though they are not suitable for every purpose (Wynn and Clarkson 2018; Gericke et al. 2016b). However, individuals also bring an understanding of particular modelling approaches from university or another company into a company, so that different approaches are used in conjunction (see Eckert and Clarkson, 2010). As the different modelling approaches express different elements, they are sometimes combined. For example, Gantt charts, expressing duration, and Pert charts, expressing task dependency, are often used together.

Empirical studies looking on method discovery and selection in general further show that practitioners look for new methods and approaches in case of new or non-routine situations (Daalhuizen and Badke-Schaub 2011), however, they not always perform a benchmarking analysis, but also rely on their experience, i.e. approaches they already know or heard of, and their intuition (Eisenmann and Matthiesen 2020), but if they are performing a benchmarking analysis they prefer to decide based on outcome- and context-specific factors (Gericke et al. 2016b). Selection criteria for process modelling approaches proposed in this paper will therefore also cover outcome- and context-specific criteria and will be evaluated together with practitioners from industry.

\section{WORKSHOP}

The workshop session started with each of the participants individually noting down all the criteria they could come up with, which resulted in 58 post-it notes. Each of the 58 notes were assigned to at least one of the following categories, which define different aspects of the process modelling environment:

- Application

- Basic logic

- Information technology (IT) tool

- Notation

- $\quad$ Process modelling approach

- $\quad$ Process modelling method

Next, the participants compared their findings and consolidated these into a set of 29 criteria, as presented in Figure 1. To ensure a common understanding of the criteria definition, eleven unbiased cluster criteria have been identified from the set of 29 criteria to select process modelling environments. These cluster criteria have been placed in the top row of Figure 1 and have been highlighted in green. The other eighteen criteria have been assigned to one or two of the cluster criteria, e.g., Formality and Robustness have been assigned to Executability, and Effort has been assigned to both Scalability and Availability. In the upcoming section, the eleven cluster criteria are described in more detail.
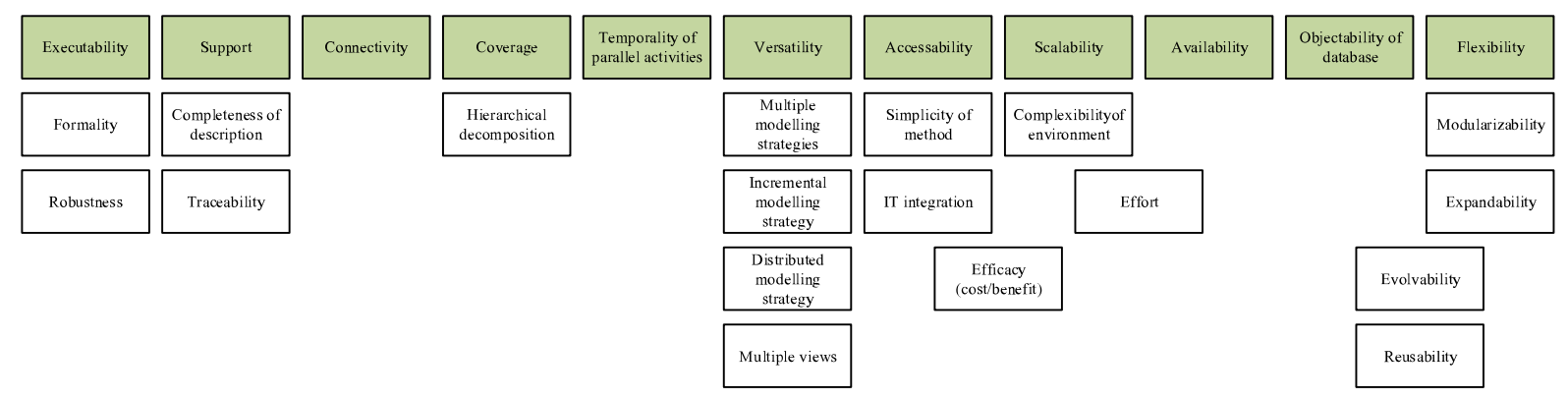

Figure 1: Eleven unbiased cluster criteria, highlighted in green, have been selected from the set of 29 selection criteria that have been identified during the workshop. 


\section{LITERATURE REVIEW}

To validate the initially defined criteria depicted in Figure 1, a literature review was conducted. The focus was on engineering design process modelling approaches, however, also process models of other fields of application such as business process modelling were considered. During this literature review some of the initial criteria were adapted. Accessibility was renamed as Integrability. Support and Availability were clustered under the term Effort. Objectability of Database was refined to Linkability to Database. Further, Verification/Validation and Viscosity were added. The final criteria descriptions can be found in the following Chapter 6, in Table 2.

All criteria, associated synonyms, as well as the respective references can be found in Table 1. For example, our criterion of "executability" is reflected in the work of other authors under different terms. Luo and Alex Tung (1999) provide a list of important characteristics regarding modeling methods, which among others contains "Enactibility". As the authors link this term to the ability of a method to simulate and analyze processes, it is quite similar to our criterion of "Executability". By formulating requirements for modelling techniques Giaglis (2001) refers to this aspect as "Measurability". He sees this as an element in order to support process improvement. Furthermore, Kaschek et al. (2006) describe this characteristic as "Theoretical foundation", which they argue reflects the ability of a model to be converted into a simulation model. Our second criterion "Connectivity" can be compared to the notion of "Tightness of the connection between two nodes", as described by Vanderfeesten et al. (2008). Similar to our interpretation they link this attribute to the ability of a model to connect internal elements and they even provide a formalized relationship for this. Under the term "Integration" Sage and Lynch (1998) presented a rather broad definition of what we called "Integrability". They explicitly refer to blending, coordinating, or incorporating new components in existing systems. Our exact definition of the term is more specific and tailored to process modelling. Another aspect comparable to our criterion "Coverage" can be found in Kaschek et al. (2006) and Recker and Mendling (2016). They call it "Maturity" and divide it into multiple subcategories. In course of describing data believability, Prat and Madnick (2008) present the term "temporality", which matches our understanding of this term. Finally, multiple definitions of what we call "Versatility" are presented by Browning (2018), Kaschek et al. (2006) and Krueger et al. (2000). The term scalability is used directly by Luo and Alex Tung (1999). Their definition is also in line with our understanding, considering this term as the potential of process models to be used for large systems. Kaschek et al. (2006) also consider this factor to select business process modelling approaches, but in their definition, it is called "granularity". They also indirectly present a description for one of the most common criterion "effort". Yet there is a plethora of different terms used such as performance (Browning 2018), complexity, time, work intensity (Wynn and Clarkson 2018) or cost (Kaschek et al. 2006). The ability to connect the model to a database is often called connectivity (e.g., Browning 2018; Vanderfeesten et al. 2008; Wynn and Clarkson 2018). Similar to "effort", also the ability to verify and validate a model is often considered as an important factor in literature. There are plenty of synonyms used for this criterion. The most common ones are listed in Table 1. Flexibility also occurred in the literature. Here, predominantly concrete actions are taken as factors to describe the expected flexibility of a process model - such as "nesting" (Kaschek et al. 2006). Nonetheless, here "flexibility" is considered as general enough to cover the other presented terms.

The only criterion, where no synonym could be found in literature is viscosity - predominantly as it is often seen as a part of "effort". However, we adopted the term from the cognitive dimensions framework by Green and Petre (1996), which describes criteria for the usability of visual programming environments. 
Table 1: Comparison of selected criteria with related criteria from literature (the number in square brackets behind the synonym indicates the position of the associated reference in the last column).

\begin{tabular}{|c|c|c|}
\hline Criterion & Synonyms in literature & References \\
\hline Executability & $\begin{array}{l}\text { Enactibility [1], Measurability [2], Theoretical } \\
\text { foundation [3] }\end{array}$ & $\begin{array}{l}\text { (Luo and Alex Tung 1999; Giaglis } \\
\text { 2001; Kaschek et al. 2006) }\end{array}$ \\
\hline Connectivity & $\begin{array}{l}\text { Integration [1], Tightness of the connection } \\
\text { between two nodes [2] }\end{array}$ & $\begin{array}{l}\text { (Browning 2018; Vanderfeesten et al. } \\
\text { 2008) }\end{array}$ \\
\hline Integrability & Integration & (Sage and Lynch 1998) \\
\hline Coverage & $\begin{array}{l}\text { Completeness [1], Maturity [2], Level of } \\
\text { Integration [3] }\end{array}$ & $\begin{array}{l}\text { (Kaschek et al. 2006; Recker and } \\
\text { Mendling 2016; Eckert et al. 2017) }\end{array}$ \\
\hline Temporality & Temporality & (Prat and Madnick 2008) \\
\hline Versatility & $\begin{array}{l}\text { Effectiveness [1], Flexibility [2], Ability to } \\
\text { cover [2], Robustness [3] }\end{array}$ & $\begin{array}{l}\text { (Browning 2018; Kaschek et al. } \\
\text { 2006; Krueger et al. 2000) }\end{array}$ \\
\hline Viscosity & - & (Green and Petre 1996) \\
\hline Scalability & Scalability [1], Granularity [2] & $\begin{array}{l}\text { (Luo and Alex Tung 1999; Kaschek } \\
\text { et al. 2006) }\end{array}$ \\
\hline Effort & $\begin{array}{l}\text { Performance [1], Complexity [2], Time [2], } \\
\text { Work intensity [2], Cost [3] }\end{array}$ & $\begin{array}{l}\text { (Browning 2018; Wynn and Clarkson } \\
\text { 2018; Kaschek et al. 2006) }\end{array}$ \\
\hline $\begin{array}{l}\text { Linkability to } \\
\text { database }\end{array}$ & Connectivity & $\begin{array}{l}\text { (Browning 2018; Vanderfeesten et al. } \\
\text { 2008; Wynn and Clarkson 2018) }\end{array}$ \\
\hline $\begin{array}{l}\text { Verification / } \\
\text { Validation }\end{array}$ & $\begin{array}{l}\text { Evaluation [1], Demonstration [2], Usability } \\
\text { [3], Success [3], Flexibility [3], Correctness [4] }\end{array}$ & $\begin{array}{l}\text { (Vanderfeesten et al. 2008; Wynn } \\
\text { and Clarkson 2018; Sadiq et al. 2005; } \\
\text { Meyer et al. 2013) }\end{array}$ \\
\hline Flexibility & $\begin{array}{l}\text { Versatility [1], Reusability [1], Evolution [2], } \\
\text { Nesting [3], Exchangeability [3], Mapability } \\
\text { [3], Formality [4] }\end{array}$ & $\begin{array}{l}\text { (Browning 2018; Giaglis 2001; } \\
\text { Kaschek et al. 2006; Wynn and } \\
\text { Clarkson 2018) }\end{array}$ \\
\hline
\end{tabular}

\section{LIST OF CRITERIA}

As described in Chapter 2, the results of the brainstorming workshop with academic experts were combined with the findings of the literature review described in Chapter 5 as well as follow-up discussions of the authors. Overall, the literature review confirmed the identified criteria. However, minor changes, as described in the previous chapter, resulted in the final list of criteria. (see Table 2.)

Table 2: Consolidated list of criteria for selecting process modelling approaches.

\begin{tabular}{|c|c|}
\hline Criterion & Description \\
\hline Ło Connectivity & $\begin{array}{l}\text { "A measure of how easily additional internal elements can be } \\
\text { connected." }\end{array}$ \\
\hline (1) & $\begin{array}{l}\text { "A measure of which different elements (artifacts, } \\
\text { stakeholder, tasks, steps, etc.) can be included by the method." }\end{array}$ \\
\hline Effort & $\begin{array}{l}\text { "A measure of the money or time a user has to invest to use } \\
\text { the tool." }\end{array}$ \\
\hline
\end{tabular}




\begin{tabular}{|c|c|}
\hline Criterion & Description \\
\hline \{0\} Ex & $\begin{array}{l}\text { "A measure of how easily a model-driven execution of the } \\
\text { process can be realized, based on the method." }\end{array}$ \\
\hline Flexibility & $\begin{array}{l}\text { "A measure of how effective a tool/method is in extending an } \\
\text { existing process model. This includes building modules, } \\
\text { reusing parts and evolutionary refinement." }\end{array}$ \\
\hline Integrability & $\begin{array}{l}\text { "A measure of how easily additional method/tools can connect } \\
\text { to the process modelling method in order to exchange } \\
\text { data/information." }\end{array}$ \\
\hline - Linkability to Database & $\begin{array}{l}\text { "A measure of how well a method / tool can be linked to a } \\
\text { database." }\end{array}$ \\
\hline Scalability & $\begin{array}{l}\text { "A measure of how large and complex a process can be while } \\
\text { it is still possible to model it with the tool/method." }\end{array}$ \\
\hline Temporality & "Assesses the ability to model temporal relationships." \\
\hline $\begin{array}{l}\text { Verification / } \\
\text { Validation }\end{array}$ & $\begin{array}{l}\text { "A measure of how transparent and unambiguous a } \\
\text { method/tool is in representing a certain process." }\end{array}$ \\
\hline$\bigoplus_{m}$ Versatility & "The ability of a method to be used for different purposes." \\
\hline 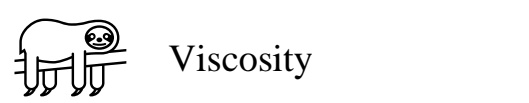 & $\begin{array}{l}\text { "A measure of how much effort is required to perform a single } \\
\text { change." }\end{array}$ \\
\hline
\end{tabular}

The first criterion assesses the ability of a modelling approach to handle interfaces- thus how easy internal elements can be connected. For example, in a design structure matrix (DSM) one can just add a link between two elements by filling the connecting cell in the matrix. On the other hand, textual descriptions of design processes make it very difficult to connect individual elements without adding numerous explanations. Closely related to "connectivity" is also the factor of "coverage". It is not only about linking internal elements, but also important to consider which different elements need to be modelled, considered, and connected. These elements can be e.g., persons, artifacts, tasks, steps, etc. While a Gantt-chart can only consider activities, events, and at maximum responsibilities, Business Process Modelling Notation (BPMN) can in addition consider artifacts (Standard ISO/IEC 19510:2013). "Effort" is the most obvious criterion, assessing both the material as well as the immaterial effort that needs to be put initially into the modelling approach. This factor for example also covers previous knowledge of the user and thus how easy he or she can gain mental access to the method. "Executability" on the other hand is more advanced. This factor assesses the possibility of a method to be executed in an automated way. For example, BPMN models or Flowchart models can be turned in an automated workflow, whereas there is no straight forward possibility to execute a process DSM automatically. A criterion which might justifies high effort is "flexibility". This factor assesses to which extent a process model can be extended or adapted after building it. Also "integrability" can be a reason to accept higher effort. Here, the fit of the process modelling approach with the existing tool/method landscape of the company at hand is considered. Especially standardized interfaces are required to allow for seamless data exchange. A high integrability is also a very important prerequisite 
for "executability". It is also tightly linked to the next factor "linkability to database". This criterion puts the focus on the possibility to integrate also empirical data from a database. So, for example, whether it is possible to automatically update a process model based on gathered metadata from the project, as it was proposed in Piccolo et al. (2018). Connected to "flexibility" is the criterion "scalability". It is also one of the most important factors, as it evaluates the ability of an approach to model huge processes, while still being comprehensible. In contrast to "coverage" it is not about how many different elements can be considered, but how many elements in total.

In processes often not only the sequence of activities or steps are of relevance, but also the duration of these activities. To pay respect to this fact, we introduced the factor "temporality". Not all approaches allow for modelling durations, or temporal relationships. A Gantt-chart of course per se considers the temporality of a process - a flow chart on the other hand only indicates the sequence of the steps.

It also matters whether a process model is supposed to be used for communication. To ensure a good suitability for communication, the used approach needs to allow for a transparent and unambiguous modelling. This is not only for communication purposes important, but also for validation and verification of the model at hand. Thus, we introduced the criterion "verification/validation".

Again, a good reason to justify higher effort is, when a process modelling approach offers a high "versatility". By considering this criterion it is possible to assess the ability of a built process model to be used for different purposes. For example, whether the same model can be used for multiple followup analyses such as resource allocation, sequencing of tasks, health monitoring of projects, change management, etc. Finally, one should consider "viscosity" in the process of benchmarking modelling approaches. In contrast to "flexibility" it does not evaluate the ability of an approach to allow for a posteriori changes of the process model, but the effort required to perform this change.

\section{DIscussion}

The interviews revealed that the interviewees' companies did not go through a systematic selection process; rather, the engineers responsible for process modelling use the models they were accustomed to, instead of undergoing a systematic benchmarking. Also, the companies do not provide a list of criteria for the selection and are not planning to do so. However, both interviewees welcomed the idea of having a set of criteria to make their own judgements and pointed out that this would also help them to express their recommendations. From their experience, this would lead to a much more purpose oriented, efficient, and tailored application of methods, which would also support acceptance of these models within the company. Especially, since current development methodologies, such as agility, pose new challenges to process modellers.

Selecting criteria to assess modelling approaches can be error-prone in multiple ways. To lower this risk, interviews with two industry representatives were conducted to understand whether this list is clear, complete, and intuitive. First, the completeness of the list was assessed. Even though a systematic search and evaluation process had been applied (see Chapter 2) it could not be taken for granted that all relevant criteria had been captured. Especially in some fields of industry where modelling techniques need to meet stringent requirements and multiple stakeholder groups, different (maybe more exceptional) criteria might have been required. However, the interview partners confirmed that the most critical aspects of evaluating modelling approaches were captured and formally described.

A second potential weak spot of the criteria list could have been its clarity. While some criteria, like Linkability to Database or Temporality, are less likely to be misunderstood, others like Viscosity or Flexibility might be unintuitive. Subsequently, this might lead to a rejection of the overall concept since users are unsure how to interpret the single definitions or may not be able to differentiate between them. In the initial evaluation with the industry representatives, only the criterion "Verification/Validation" was considered as too vague.

Finally, the list of criteria also might be too superficial. We chose this granularity since it provided an acceptable compromise between the level of detail necessary to characterize modelling techniques and the number of criteria to select from. However, the final selection tool, discussed in Helten et al. (under review) will have the option to expand every criterion and display the list of sub-criteria, which are connected to this element of the list. 


\section{CONCLUSION \& OUTLOOK}

This paper presents a list of criteria with respective descriptions, which can be used for benchmarking and selecting process modelling approaches. Purpose of this publication was to systematically identify useful criteria for benchmarking process modelling approaches. Even though the applicability so far is quite limited, it lays a foundation for a comprehensive benchmarking tool. Thus, for unexperienced practitioners the criteria can already guide them in a systematic selection of suitable approaches. For academics, this paper provides a consistent overview of criteria. This list can also be used to systematically describe, but also to enhance existing process modelling approaches, by improving the respective criteria.

In the future, a multi-criteria decision-making tool based on AHP (Analytic Hierarchy Process) proposed by Saaty (1990) will be used to carry out a pairwise comparison of the different criteria with regards to the scenarios proposed in Helten et al. (under review) to assess the suitability of the criteria against an intuitive selection of modelling approaches. The tool generates an aggregate solution based on the assessment by multiple users based on fuzzy numbers (see Liu et al. 2020). The resulting mapping of criteria and process modelling approaches will lay the foundation for a benchmarking tool, that can be provided to practitioners. Here, one can either use predefined recommendations with respect to predefined scenarios and personas (which are described by Helten et al. (under review)), or by an individualized assessment of the previously presented criteria. In addition to the benefits for practitioners, this benchmarking can also provide insights on the weighting and selection of criteria, based on the user interaction. This metadata can than be used to identify needs and requirements for new process modelling approaches.

\section{ACKNOWLEDGMENTS}

The authors of this publication would like to thank all participants of the MMEP workshop, as well as the two interviewed experts.

\section{REFERENCES}

Aguilar-Savén, Ruth Sara (2004): Business process modelling: Review and framework. In International Journal of Production Economics 90 (2), pp. 129-149. http://doi.org/10.1016/S0925-5273(03)00102-6

Browning, Tyson R. (2018): Building models of product development processes: An integrative approach to managing organizational knowledge. In Syst Eng 21 (1), pp. 70-87. http://doi.org/10.1002/sys.21421

Browning, Tyson R.; Ramasesh, Ranga V. (2007): A Survey of Activity Network-Based Process Models for Managing Product Development Projects. In Production and Operations Management 16 (2), pp. 217-240. http://doi.org/10.1111/j.1937-5956.2007.tb00177.x

Cameron, I. T.; Ingram, G. D. (2008): A survey of industrial process modelling across the product and process lifecycle. In Computers \& Chemical Engineering 32 (3), pp. 420-438. http://doi.org/10.1016/j.compchemeng.2007.02.015

Checkland, Peter (1999): Soft systems methodology. A 30-year retrospective. Systems thinking, systems practice. Peter Checkland. Chichester: Wiley.

Daalhuizen, Jaap; Badke-Schaub, Petra (2011): The use of methods by advanced beginner and and expert industrial designers in non-routine situations: a quasi-experiment. In International Journal of Product Development 15 (1-3), pp. 54-70. http://doi.org/10.1504/IJPD.2011.043661

Eckert, Claudia M.; Clarkson, P. John (2010): Planning development processes for complex products. In Res Eng Design 21 (3), pp. 153-171. http://doi.org/10.1007/s00163-009-0079-0

Eckert, Claudia M.; Wynn, David C.; Maier, Jakob F.; Albers, Albert; Bursac, Nikola; Xin Chen, Hilario L. et al. (2017): On the integration of product and process models in engineering design. In Des. Sci. 3, p. 137. https://doi.org/10.1017/dsj.2017.2

Eisenmann, M.; Matthiesen, S. (2020): Identifying Reasons for a Lack of Method Application In Engineering Design Practice - An Interview Study. In: Proceedings of the Design Society: DESIGN Conference, vol. 1, pp. 2495-2504. https://doi.org/10.1017/dsd.2020.261

Eppinger, Steven D.; Browning, Tyson R. (2019): Design Structure Matrix Methods and Applications. Cambridge: The MIT Press.

Fleischmann, Albert; Schmidt, Werner; Stary, Christian; Obermeier, Stefan; Börger, Egon (2012): Subject-Oriented Business Process Management. Berlin, Heidelberg: Springer. https://doi.org/10.1007/978-3-642-32392-8

Gericke, K.; Eckert, C. M.; Wynn, D. (2016a): Towards a Framework of Choices Made During the Lifecycles of Process Models. In DS 84: Proceedings of the DESIGN $201614^{\text {th }}$ International Design Conference, pp. $1275-1284$. 
Gericke, Kilian; Kramer, Julia; Roshuni, Celeste (2016b): An exploratory study of the discovery and selection of design methods in practice. In Journal of Mechanical Design 138 (10).

Giaglis, George M. (2001): A Taxonomy of Business Process Modeling and Information Systems Modeling Techniques. In International Journal of Flexible Manufacturing Systems 13 (2), pp. 209-228. http://doi.org/10.1023/A:1011139719773

Green, T.R.G.; Petre, M. (1996): Usability Analysis of Visual Programming Environments: A 'Cognitive Dimensions’ Framework. In Journal of Visual Languages \& Computing 7 (2), pp. 131-174. http://doi.org/10.1006/jvlc.1996.0009

Helten, Katharina; Eckert, Claudia M.; Gericke, Kilian; Vermaas, Pieter (2021): Concept for a Persona Driven Recommendation Tool for Process Modelling Approaches. In Review. In: Proceedings of the $23^{\text {rd }}$ International Conference on Engineering Design (ICED21). Gothenburg, Sweden, August 16-20, 2021. The Design Society: Cambridge University Press.

Standard ISO/IEC 19510:2013, 11/19/2020: Information technology - Object Management Group Business Process Model and Notation. Available online at https://www.iso.org/standard/62652.html, checked on 03/18/2021.

Kaschek, Roland; Pavlov, Roman; Shekhovtsov, Vladimir A.; Zlatkin, Sergiy (2006): Towards selecting among business process modeling methodologies. In 1617-5468. Available online at https://dl.gi.de/handle/20.500.12116/24153.

Krueger, Norris F.; Reilly, Michael D.; Carsrud, Alan L. (2000): Competing models of entrepreneurial intentions. In Journal of Business Venturing 15 (5-6), pp. 411-432. http://doi.org/10.1016/S08839026(98)00033-0

Liu, Yan; Eckert, Claudia M.; Earl, Chris (2020): Assessing Suppliers for Complex Products From the Perspective of Power. In IEEE Trans. Eng. Manage., pp. 1-17. http://doi.org/10.1109/TEM.2020.2988056

Luo, Wenhong; Alex Tung, Y. (1999): A framework for selecting business process modeling methods. In Industr Mngmnt \& Data Systems 99 (7), pp. 312-319. http://doi.org/10.1108/02635579910262535

Ouertani, M. Z.; Grebici, K.; Gzara, L.; Blanco, E.; Rieu, D. (2007): DEPNET: A Methodology for Identifying and Qualifying Dependencies Between Engineering Data. In Frank-Lothar Krause (Ed.): The Future of Product Development. Proceedings of the $17^{\text {th }}$ CIRP Design Conference. Berlin, Heidelberg: SpringerVerlag Berlin Heidelberg, pp. 319-330. https://doi.org/10.1007/978-3-540-69820-3_32

Piccolo, Sebastiano A.; Trauer, Jakob; Wilberg, Julian; Maier, Anja M. (2018): Understanding Task Execution Time in Relation to the Multilayer Project Structure: Empirical Evidence. In: DS 96: The $20^{\text {th }}$ International DSM Conference. 20 ${ }^{\text {th }}$ International Dependency and Structure Modelling Conference (DSM 2018), pp. 129-138.

Prat, Nicolas; Madnick, Stuart (2008): Measuring Data Believability: A Provenance Approach. In: Proceedings of the $41^{\text {st }}$ Annual Hawaii International Conference on System Sciences (HICSS 2008). $200841^{\text {st }}$ Annual Hawaii International Conference on System Sciences. Waikoloa, HI, 07.01.2008 - 10.01.2008: IEEE, p. 393. https://doi.org/10.1109/HICSS.2008.243

Recker, Jan; Mendling, Jan (2016): The State of the Art of Business Process Management Research as Published in the BPM Conference. In Bus Inf Syst Eng 58 (1), pp. 55-72. http://doi.org/10.1007/s12599-015-0411-3

Saaty, Thomas L. (1990): How to make a decision: The analytic hierarchy process. In European Journal of Operational Research 48 (1), pp. 9-26. http://doi.org/10.1016/0377-2217(90)90057-I

Sage, Andrew P.; Lynch, Charles L. (1998): Systems integration and architecting: An overview of principles, practices, and perspectives. In Syst Eng 1 (3), pp. 176-227. http://doi.org/10.1002/(SICI)15206858(1998)1:3\&lt;176AID-SYS3>3.0.CO;2-L

Stacey, Martin; Eckert, Claudia; Hillerbrand, Rafaela (2020): Process models: plans, predictions, proclamations or prophecies? In Res Eng Design 31 (1), pp. 83-102. http://doi.org/10.1007/s00163-019-00322-8

Stapenhurst, Tim (2009): The Benchmarking book. A how-to-guide to best practice for managers and practitioners. Amsterdam: Elsevier. Available online at http://site.ebrary.com/lib/alltitles/docDetail.action?docID=10294740.

Vanderfeesten, Irene; Reijers, Hajo A.; Mendling, Jan; van der Aalst, Wil M. P.; Cardoso, Jorge (2008): On a Quest for Good Process Models: The Cross-Connectivity Metric. In Zohra Bellahsène, Michel Léonard (Eds.): Advanced Information Systems Engineering. 20 $0^{\text {th }}$ International Conference, CAiSE 2008 Montpellier, France, June 16-20, 2008 Proceedings. Berlin, Heidelberg, 2008. Berlin, Heidelberg: Springer-Verlag Berlin Heidelberg (Lecture Notes in Computer Science, 5074), pp. 480-494. https://doi.org/10.1007/978-3-540-69534-9_36

Wynn, David C.; Clarkson, P. John (2018): Process models in design and development. In Res Eng Design 29 (2), pp. 161-202. http://doi.org/10.1007/s00163-017-0262-7

Wynn, David C.; Eckert, Claudia M.; Clarkson, P. John (2006): Applied Signposting: A Modeling Framework to Support Design Process Improvement. In: Volume 4a: $18^{\text {th }}$ International Conference on Design Theory and Methodology. ASME 2006 International Design Engineering Technical Conferences and Computers and Information in Engineering Conference. Philadelphia, Pennsylvania, USA, September 10-13, 2006: ASME, pp. 553-562. https://doi.org/10.1115/DETC2006-99402 